\title{
Practical Approach to Implement Koha Data Backup through Cloud Computing In Benue State University
}

\author{
IGBUDU Murphy Tersoo ${ }^{1}$, ASEN Anita Tersur ${ }^{2}$, VER Akuhwa ${ }^{3}$ \\ ${ }^{I}$ Head of Virtual Library, Benue State University Library \\ ${ }^{2}$ Head of Cataloguing and Classification, Benue State University Library \\ ${ }^{3}$ Virtual Library, Benue State University Library \\ DOI: $\underline{\text { https://dx.doi.org/10.51244/IJRSI.2021.8409 }}$
}

\begin{abstract}
The study is designed to document the Practical Approach to implement koha data backup through cloud computing at Benue State University. The study is guided by three objectives. The research is anchored on the experience of staff of Benue State University Library. This research made use of Linux cronjob command to schedule an automatic process that runs every 30 minutes to take koha data backup to a dropbox account that was created and synchronized with the koha server system. The focus of this research is to secure the koha database through cloud computing and render it less prone to data loss. Also, to enable librarians have a better knowledge of koha databackup, and implement cloud backup themselves without consulting a paid vendor. Screenshots of practical measures used during the data backup and retrieval are shown below from figure 1-13. Figure 1-8 shows the implementation of koha cloud backup and 9-13 shows retrieving koha database from cloud backup. In conclusion, this research work has brought out a simple approach to ensure the security of the koha database by using cloud computing to backup the koha database and retrieve the same through any computer connected to the internet.
\end{abstract}

Keywords: Cloud Computing, Koha, Data Backup, Library, Benue State University

\section{INTRODUCTION}

$I^{\prime}$ nformation storage and retrieval are one of the core functions of every library system. In recent times koha, as one of the library management software is used to carry out daily library routine operations with reduced efforts leading to efficient and effective library services. Using koha to carry out library operations generates a large volume of data that is backed up on the hard drive of the local server system. The koha database is frequently updated, maintained and reports are generated to enhance better managerial decisions. However, Backing up koha data on a local server system alone is not enough as the system can crash, get infected by viruses, or be affected by other natural disaster like fire and thunder, or water leading, to data loss. According to Cashman et al. in Kisaulu (2015), no matter how well computer-based information systems are designed, they often experience problems such as hardware failures, software errors or users' mistakes. This often leads to data loss. As a result of this, other external storage media are preferred for backup of the koha database. These external storage media are physical media and cloud storage.

Gosavi and Shinde (2012) maintained that moving library data to the cloud may be a leap of faith for some library professionals. This is because, cloud computing is a new technology that can backup large volumes of data on a distributed network system. With this, patrons can retrieve information faster and local server space is maximized. Gosavi and Shinde further stressed that Cloud computing or Information Technology infrastructure that exists on the internet, often gives users increased capacity and less need for updates, maintenance, and have gained wider acceptance among librarians.

\section{OBJECTIVES OF THE STUDY}

The objectives of the study seek to find out:

1. Systems requirements for integrating cloud computing on koha

2. Implementation of koha cloud backup

3. Retrieving koha database from cloud backup

Statement of the problem

Populating the koha database with library collections is a tedious and time consuming task. After the entire process, it become frustrating to loss the entire data. This have left many libraries on a cross road on whether to still start automation or continue with only the manual process of carrying out daily library operations. The primary cause of the koha data loss may be lack of proper data backup or use of external storage devices such as flash drives, CD ROM, external hard drives and diskettes to back up data which are vulnerable and can easily get destroyed. Cloud computing have proved, and is one of the most effective ways, which koha data backup is carried out. This research work is a practical approach to implementing the koha backup through cloud computing and to access same through any computer connected to internet.

\section{CONCEPTUAL CLARIFICATION}

\section{Cloud Computing Services}

cloud computing are a collection of hardware, software and other telecommunication services that are hosted on the internet and that can be accessed on client computers, and over the network. According to (Sambrani and Rajashekarappa 2016), Cloud computing allows end users to run software applications and access data from anywhere, any time and from any computer. 
Voorsluys et al., in Das and Mandal (2013) maintained that Cloud computing providers offer, their services according to three fundamental models, namely: Software as a Service (SaaS), Platform as a Service (PaaS) and Infrastructure as a service (IaaS). This three models, of cloud computing are the basis that form other types of cloud services.

\section{Software as a Service (SaaS)}

SaaS is a cloud computing service where a software that is in the cloud is allowed access to upon registration or subscription. Access level might be determined by either payment of little charges or free access. Example of such services are Dropbox, gmail, google drive, youtube etc.

\section{Platform as a Service (PaaS)}

PaaS is a cloud computing service where a computing platform like an Operating system, etc is provided on a monthly rental basis. Some of the major cloud computing vendor providing PaaS is Amazon, Microsoft and Google.

\section{Infrastructure as a Service (IaaS)}

IaaS is a cloud computing model where computing infrastructure, and hardware services such as processors, memory, networks and virtual machines are given to users for a specific duration for a certain amount.

\section{Data Backup}

Data backup, is the copying of program files and data from a computer hard drive for a period of time to safeguard and protect the data against equipment failure or catastrophe. Doyle in Kisaulu (2015) also defined backup files as a copy of a file which can be used in the event of the original file being corrupted or damaged.

\section{Types of Backups Performed}

Kisaulu (2015) stated that there are different types of backup as mentioned below.

\section{"Full Backup}

A full backup is the starting point for all other types of backup, and contains all the data in the folders and files that have been selected for back up. As full backup stores all files and folders, frequent full backups result in faster and simpler restore operations; other backup types may take longer to restore. This backup type is costly in terms of effort, time and the storage capacity requirements

\section{Differential backup}

A differential backup contains all files that have changed since the last full backup. The advantage of a differential backup is that it shortens restore time compared to a full backup or an incremental backup. However, if you perform the differential backup too many times, the size of the differential backup might grow to be larger than the baseline full backup

\section{Incremental backup}

An incremental backup stores all files that have changed since the last full, differential or incremental backup. The advantage of an incremental backup is that it takes the least time to complete. However, during a restore operation, each incremental backup must be restored, which could result in a lengthy restore job .

\section{Mirror Backups}

A mirror backup is a straight copy of the selected folders and files at a given instant in time. A mirror is the fastest backup method because it copies files and folders to the destination without any compression. However, the increased speed has its drawbacks in that it requires larger storage space and it cannot be password protected .

Irrespective of the type of backup employed, The safety of koha data depends largely on the backup media that is used. Backup media includes, magnetic disk, magnetic tape, optical disk, network attached storage and cloud storage". (p.11-12)

\section{koha}

"The name Koha comes from a Maori term for a "gift" or "donation". Koha was created in 1999 by Katipo Communications for the Horowhenua Library Trust in New Zealand. The first installation went live in January of 2000 (koha wiki, 2019)".

Using koha ILS eliminate any vendor lock in, subscription and upgrade charges because of most libraries low budget. Koha have all the modules you would expect in a fully-functional library software - acquisition, serials,circulation,cataloguing, reports, and tools. Koha is Standards compliant - MARC 21/ UNIMARC for cataloguing, Z39.50 for copy cataloguing, UTF-8 for non-English catalogue data, and SIP2 for Radio Frequency identification(RFID) integration.

"Muller (2011) supports this by stating that Koha ILS is the most complete Free and Open Source Software/Integrated Library System (FOSS/ILS) because of a number of functions including routing periodicals, inventory control, authorities, generation of notices to customers, order tracking, among others".

Some of the features of Koha software packages are that koha is cost effective, web based, user - friendly, multilingual, provide long term support, compliant with library standards, have the ability to process store full text electronic resources, have a flexible and open source back end database (Mysql), motivate and encourage library staff for creativity.

\section{Benue State University Library and Information Services}

Benue State University Library and Information Services (BSULIS) Makurdi Nigeria, supports the University Mission by facilitating access and use of information resources and services in support of the instructional, research and community service activities of the university community. The 
library system commenced operation from make-shift quarters at the inception of Benue State University, Nigeria in 1992. With a sitting capacity of approximately 3,000 this building currently houses about 45,000 books in monographs and 3,000, journal titles in addition to subscription databases, open access resources and e-books database.

The library automation started as far back as 2015. The library adopted koha open-source software as its Integrated Library Management (ILM) software. First version of the koha installed and customized was version 3.2. The server crashed in January, 2016. because data was backed up on the local Server System alone, the entire data could not be recovered after server crash. Then, version 17.05 was installed in-house, running on Ubuntu version 16.04LTS with Maria DB as the back end database. Currently, data such as; Accession Register, Datewise List of Books, Check in List of books, New Arrivers, Librarian Activity, Monthwise circulation report for a year, overdue with contact information, BSU Patron List by Category and Total fines, payments made, outstanding, written off and forgiven amounts are generated daily from koha server and queried using mysql statements. All these data are important to keep track of library collections and circulation. Also, to enhance speedy decisions to be taking by library management based on verifiable data deduced from the database. In order to ensure security of data, the system administrator used the Mysqldump statement to backup koha database daily. But the security of data on koha installed on physical machine is prone to data loss due to natural disaster and server crash. It was therefore pertinent to look for a way that koha server would be backing up automatically through cloud computing.

\section{Practical Approach to Implement the koha backup through} cloud computing

The cloud computing model adopted in this research work is Software as a Service (SaaS). here, Dropbox is installed and synchronized with the server machine and an automatic process is scheduled using linux cronjob utility to take backup from the koha Server System, and to Dropbox at the interval of 30 minutes.

\section{Systems Requirements to Integrate a Backup Cloud Computing on koha}

The systems requirements to Integrate a backup Cloud Computing on the koha server machine are hardware minimum requirements, software requirements and internet configuration.

\section{Hardware Minimum Requirement:}

Processor:

Pentium-4, 2.6 GHz and, higher

RAM:

2 GB

Hard Disk Drive : $\quad 500$ GB

\section{Software Requirement:}

Already Installed Koha running on any deviation of Linux operating system (Ubuntu, Centos, Fedora) and Mysql or MariaDB database.

Internet Configuration: A high speed dedicated Internet link connected to the Koha Server System.

\section{Implementation of koha cloud backup}

To implement koha cloud backup, steps 1-9 with corresponding figure 1-8 serves as a guide for installing dropbox, and scheduling a linux cronjob command that will back up the koha database within an interval of 30 minutes. This is an automated process that will run for 24 hours a day 7 days a week.

\section{Install Dropbox on Server Machine}

Open the Terminal and enter the command: sudo apt-get install nautilus-dropbox

Here you will be prompted for a sudo password. Enter a sudo password and hit the enter key. Follow the instruction until the set up files will finish downloading.

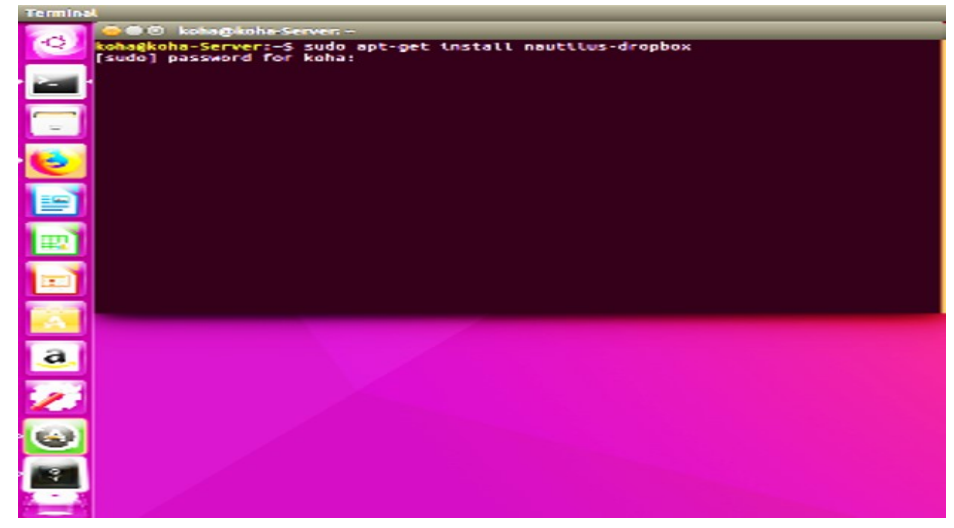

Figure 1: Terminal showing Dropbox installation command Source: BSULIS Cloud backup process, July 2019

\section{Locating Dropbox Icon}

Search your computer for Dropbox Application icon

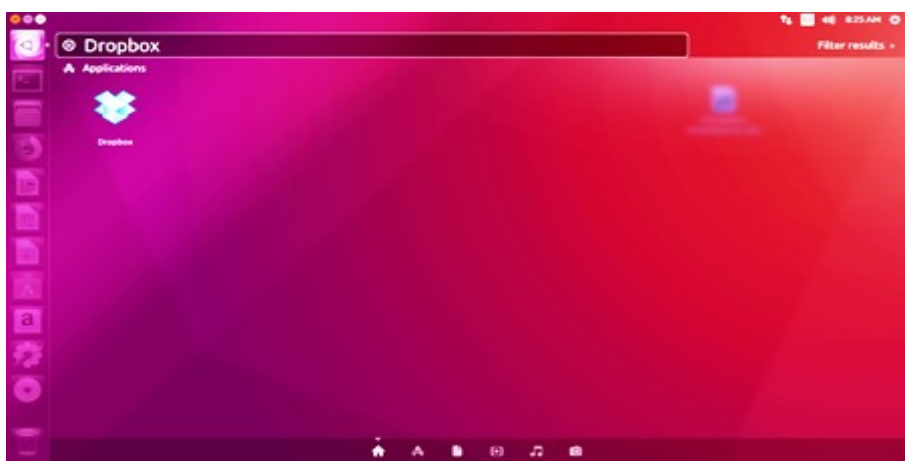

Fig2: Dropbox icon

Source: BSULIS Cloud backup process, July 2019 


\section{The Drop box Installation}

Double click on Dropbox icon and complete installation of the application

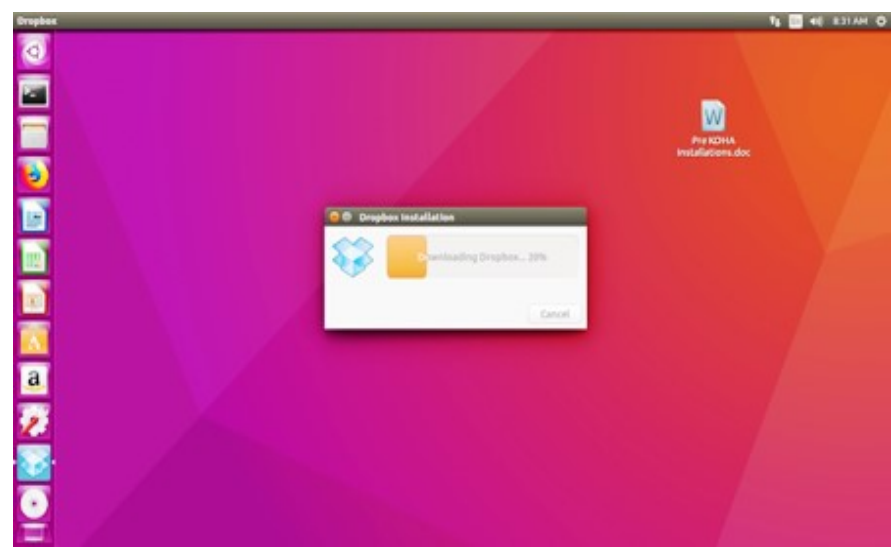

Fig 3: Dropbox Application Installation

Source: BSULIS Cloud backup process, July 2019

4. After Drop box installation on the Server System, an e-mail is needed to login. And Less secure app access from an e-mail security should be turned on.

Google account $>$ Manage your google account $>$ Security $>$ turn on Less secure app access

\section{Dropbox login}

On finishing the installation, sign in to the dropbox, for those with an existing account or create an account for those without an existing account. For this research work, we would sign in by entering an e-mail and password.

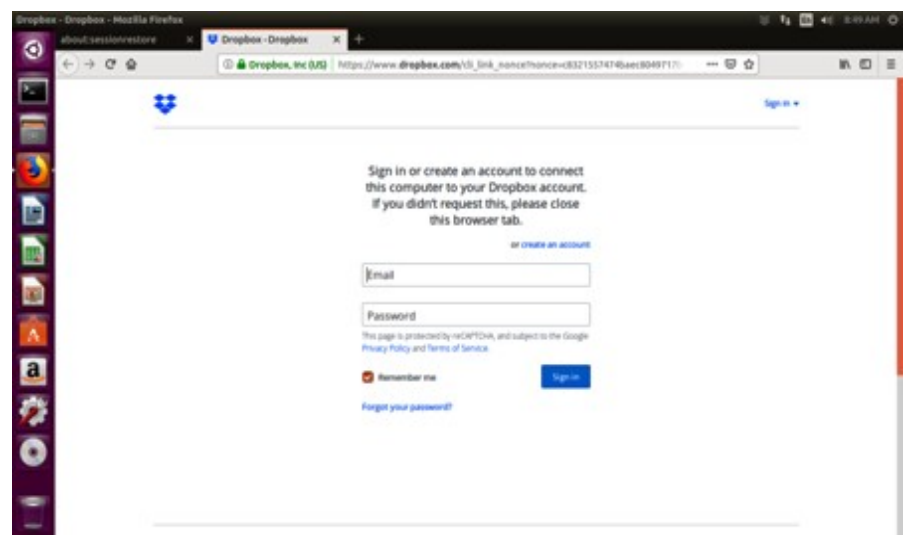

Fig. 4 Login into dropbox

Source: BSULIS Cloud backup process, July 2019

\section{Drop box synchronization with koha server}

After login, drop box will ask to connect with your computer. When you click on connect, it will synchronize with your computer and create a Folder "Dropbox" in the ubuntu user home. Where we have to point koha backup destination.
Ubuntu desktop $>$ Files $>$ koha $>$ Home $>$ Dropbox folder

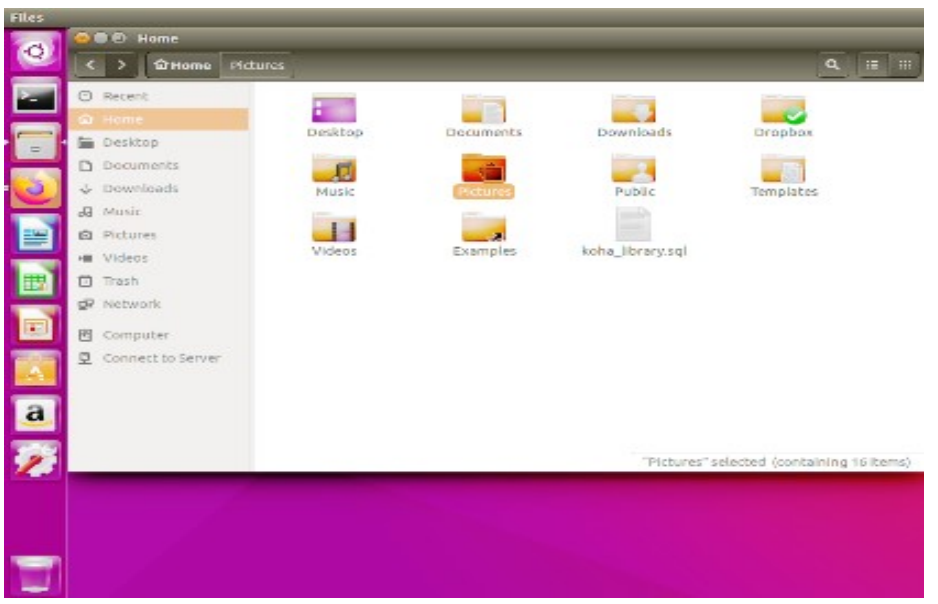

Fig 5: Dropbox Synchronization with koha server

Source: BSULIS Cloud backup process, July 2019

\section{Cronjob text editor}

Here we are going to schedule koha backup command that would backup koha database in every 30 minutes with the help of linux cronjob. This is a routine process that would run in every 30 minute automatically.

Enter root user. Then apply the following command crontab -e It will ask that a text editor to be selected. Choose " 2 " for nano text editor

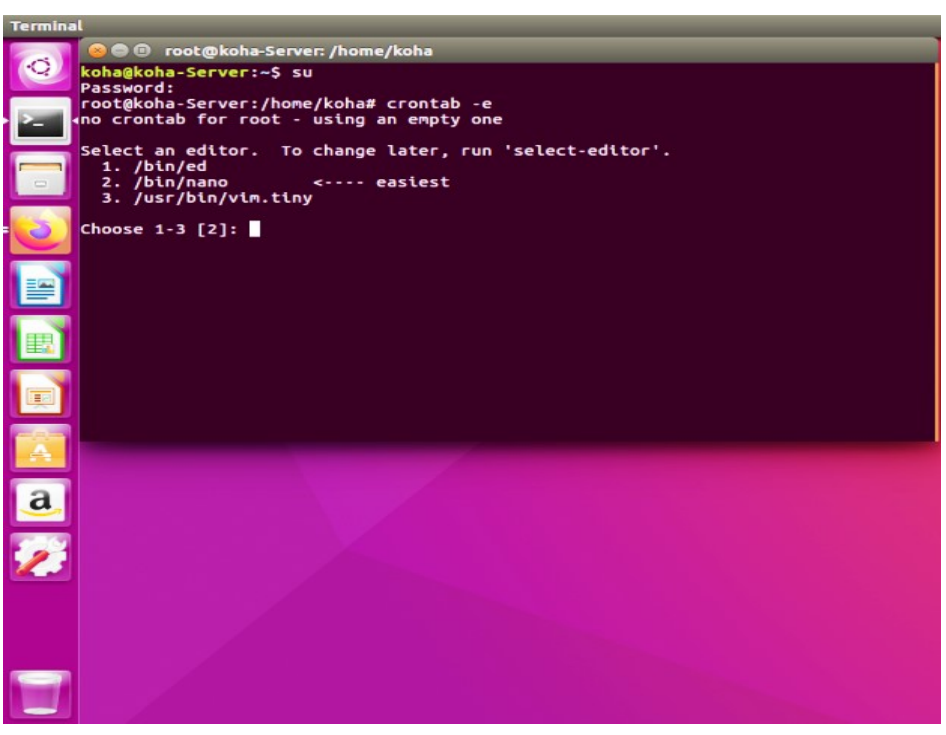

Fig 6: Entering Cron text editor

Source: BSULIS Cloud backup process, July 2019

\section{Cronjob text editor}

Use down arrow and move the cursor to the bottom of the cron file. 


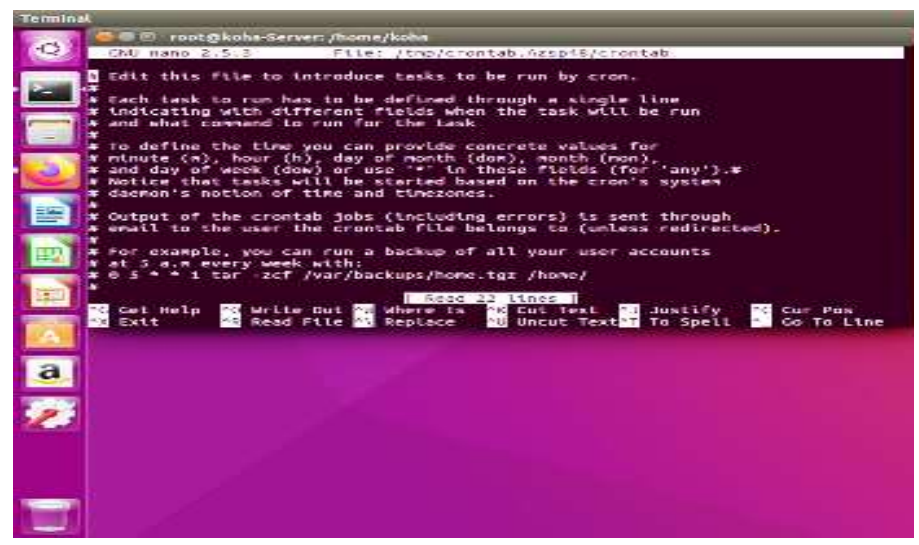

Fig 7: Cron file opened in nano text editor

Source: BSULIS Cloud backup process, July 2019

\section{Scheduling automatic backup process}

Enter the missing items to complete the command below. Then, copy and paste this command at the end of the cron file as seen in the fig. 8 below:

$* / 30 * * * *$ mysqldump -u Enter koha database username -p Enter Password for koha database Enter koha database name $\mid x z>/$ home/koha/Dropbox/Enter koha database backup name.sql.xz

After pasting the command in linux cronjob environment, on the keyboard, press control $+\mathrm{X}$ to exit cron, it will ask to save changes made on cron or not. In this case, press y to save changes then hit enter key to complete the process.

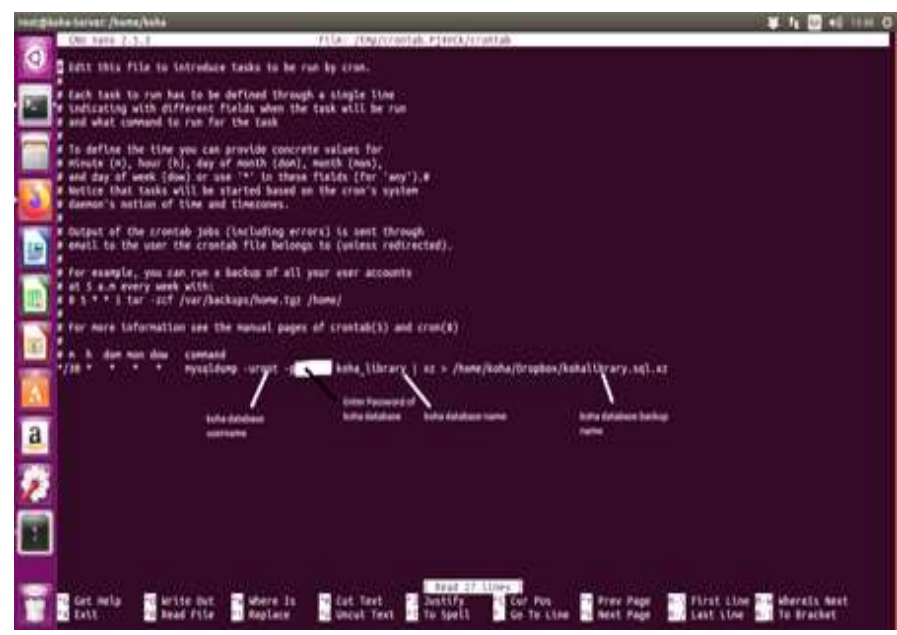

Fig 8: Setting up cron command for automatic koha database backup

Source: BSULIS Cloud backup process, July 2019

\section{Retrieving koha database from cloud backup}

Koha data backup can be retrieved in two ways. first, on local server system Home. Secondary, on any computer connected to internet. The two ways will be explained in step 10-14 and corresponding figure $9-13$.

\section{Local Server System Home}

From the local koha server system $>$ Home $>$ Dropbox folder $>$ kohalibrary.sql.xz.

\section{Open home from Ubuntu desktop}

From ubuntu desktop locate file icon and left click on it to open linux home.

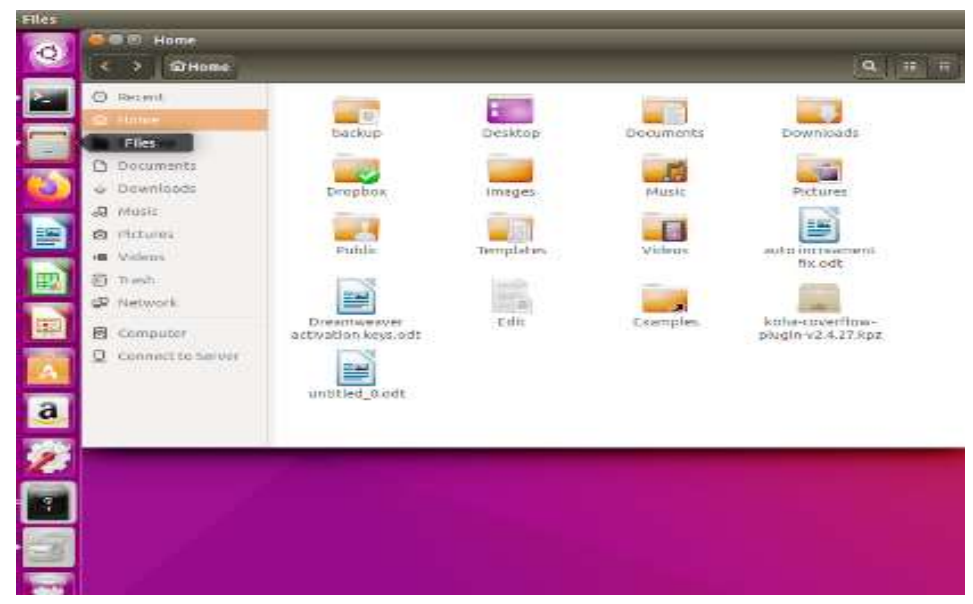

Figure 9: Linux Home

Source: BSULIS Cloud backup process, July 2019

\section{Enter into Dropbox Folder}

From linux home, double click on Dropbox folder to enter into dropbox

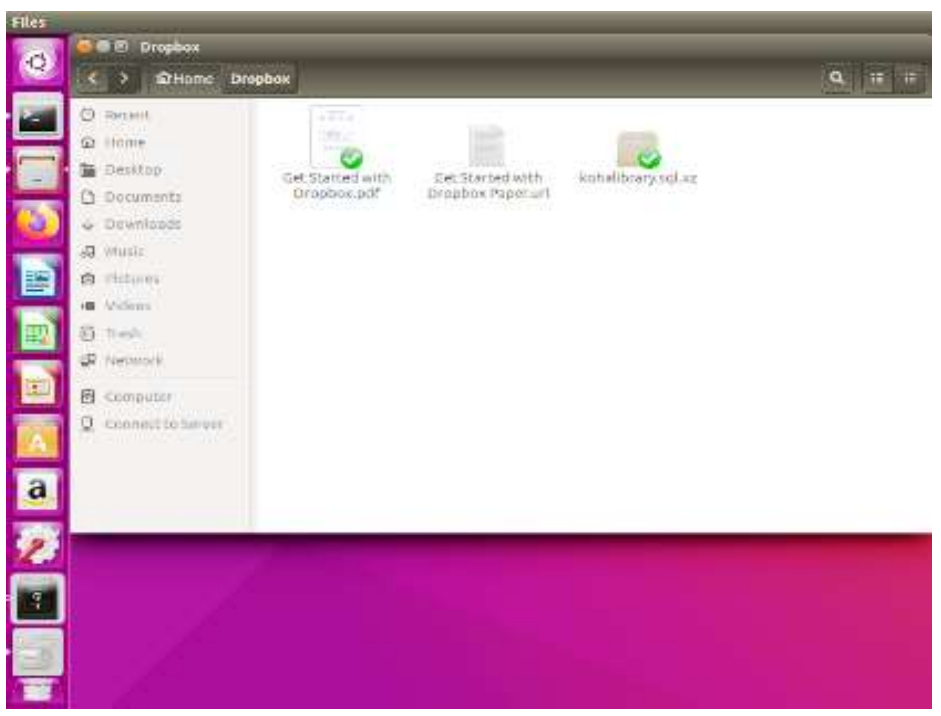

Figure 10: Dropbox

Source: BSULIS Cloud backup process, July 2019

\section{Accessing koha database}

Inside dropbox folder, locate the folder with database name.sql.xz extension and double click on it to access database. 


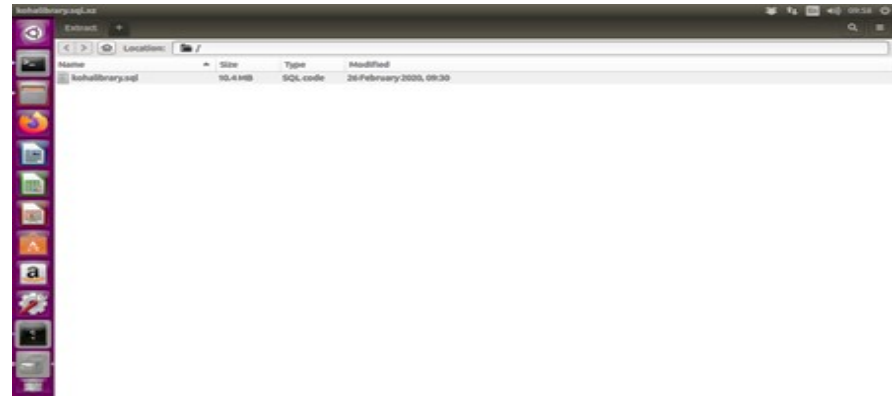

Figure 11: koha database

Source: BSULIS Cloud backup process, July 2019

\section{Accessing koha database through Any Computer Connected to Internet}

Using any computer connected to the internet, log unto https://www.dropbox.com/ then, sign in to dropbox using dropbox e-mail and password to access koha database.

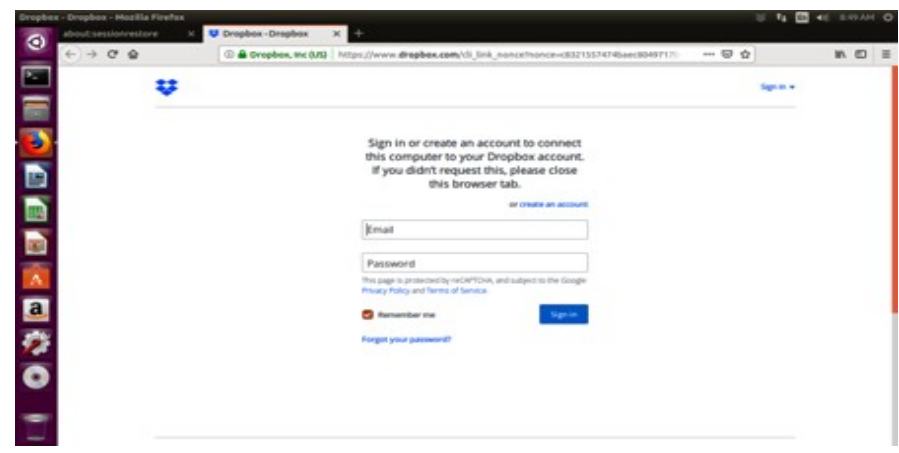

Figure 12. Dropbox login page

Source: BSULIS Cloud backup process, July 2019

\section{Access the koha database}

After entering user name and password, you will open into dropbox where database can be accessed. Here you will see the database name with .sql.xz extension. By the right-hand side of the database name, you will see a drop-down menu where you can share the database, download, comment and view database history.

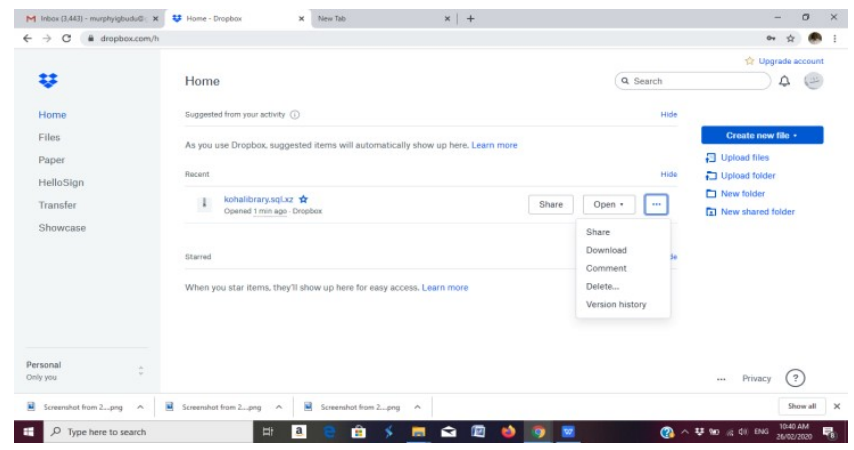

Figure 13: Accessing database through any computer connected to the Internet.

Source: BSULIS Cloud backup process, July 2019

\section{CONCLUSION}

It takes a lot of time, energy, and resources to populate the koha database with library collections. After that, data on every user, and their subsequent activities with the library like check out, check-in, circulation history etc are recorded on the koha database at real-time. This makes the database important and critical to the smooth running of the library. Due to this importance attached to the koha database, it is not enough to back up on only computer physical storage devices like external hard drives, CDROM drives, and flash or to leave the complete data on the hard drive of the physical server. These options may fail. Also, the library might be affected by natural factors such as water and fire that might completely destroy the koha database. This research work has brought out one of the likely ways to ensure the security of the koha database, which is by using cloud computing to backup the koha database and access same through any computer connected to the internet.

\section{REFERENCE}

[1] Gosavi N. and Shinde S.S (2012). Use of Cloud Computing in Library and Information Science Field. International Journal of Digital Library Sciences. 2(3). Retrieved from: http://www.ijodls.in/uploads/3/6/0/3/3603729/51-60.pdf on $22 / 02 / 2020$

[2] Das, A. K and Mandal, S (2013). Development of cloud computing in Integrated Library Management and Retrieval System. International Journal of Library and Information Science. 5(10), 394-400. DOI: 10.5897/IJLIS2013.0367

[3] Kisaulu, K. (2015). A Survey of Computer Data Backup Strategies Adopted by firms listed on the Nairobi Stoch Exchange. A Research Project Presented to School of Business, University of Nairobi. Retrieved from: http://erepository.uonbi.ac.ke/bitstream/handle/11295/13672/Kisau lu_A\%20Survey\%20of\%20Computer\%20Data\%20Backup $\% 20$ Str ategies $\% 20$ Adopted $\% 20$ by $\% 20$ Firms $\% 20$ Listed $\% 20$ on $\% 20$ the $\% 2$ 0Nairobi\%20Stock\%20Exchange.pdf?sequence $=3$ on $22 / 02 / 2020$

[4] Koha (2017). https://koha-community.org Retrieved on $22 / 02 / 2020$

[5] Library Handbook(2019). Benue State University. Mark-On Press Nig. Ltd. Makurdi.

[6] Muller, T. (2011). How to choose a free and open-source integrated library system. International digitallibraryperspectives.27(1):57-78.Retrievedfrom http://emeraldinsight.com/1065-075X.htm on 22/02/2020

[7] Sambrani, Y and Rajashekarappa (2016). Efficient Data Backup Mechanism for Cloud Computing. International Journal of Advanced Research in Computer and Communication Engineering. 5(7) DOI 10.17148/IJARCCE.2016.5719.

[8] Vimal, K. V. (2020). koha geek Blogspot. Retrieved from http://kohageek.blogspot.com/ on 22/02/2020 